\title{
Should optics be taught to optometry students?
}

\author{
V. Nourrit
}

V. Nourrit, "Should optics be taught to optometry students?," Proc. SPIE 9666, 11th Education and Training in Optics and Photonics Conference, 966616 (5 June 2009); doi: 10.1117/12.2208034

SPIE Event: Eleventh International Topical Meeting on Education and Training in Optics and Photonics, 2009, St. Asaph, United Kingdom 


\title{
Should Optics be taught to Optometry students?
}

\author{
V. Nourrit \\ The University of Manchester, Faculty of Life Sciences \\ Moffat Building, Sackville Street PO Box 88 \\ Manchester, M60 1QD, UK \\ Vincent.Nourrit@manchester.ac.uk
}

\begin{abstract}
Though developed out of physics and optics, the optometric profile in the UK has shifted towards a healthcare professional. As a result, optometry students are now stretched between numerous courses as diverse as microbiology, legal aspects related to practice, mathematics, vision or pharmacology. The importance of optics is still affirmed by regulating bodies and universities worldwide, but many students, particularly those with a relatively weak background in mathematics and physics, question the relevance of this teaching and engage reluctantly with this topic. In order to evaluate the importance of optics as part of the optometry curriculum, to improve the satisfaction of our students and to best suit their needs as future Optometrists, we first reviewed the place of optics in the optometry curricula across Europe. It appears that there are two main divisions: some have adopted a biomedical focus, well illustrated by UK universities while others have adopted a more optics/physics emphasis as in some German program. In addition to this review, we carried out a survey among Manchester Optometry alumni asking them how relevant they consider the classic teaching in optics (geometrical, physical and visual optics) to be to their subsequent career. The results of this survey will be discussed in detail. It appears that though predominantly favourable and against a reduction in the amount of optics taught, a relatively large percentage is in favour of a reduction and consider that what they learnt during their studies has not been useful to them professionally (over $20 \%$ for geometrical optics). In this context, a solution could be to increase the profile of the different professional opportunities available to graduates (optics, marketing, customer service, etc.). The simplest solution is however to take advantage of the wonderful potential of relevant optometric situations for the teaching of the fundamental optical principles. To conclude this presentation, we give a number of examples of how optometric applications can be used to introduce all the main optical phenomena.
\end{abstract}

\section{Introduction}

The history of Optometry is strongly related to the history of Optics. Philosophers of Antiquity speculated not only about the nature of light, but also about how vision is carried out in the body (e.g. Empedocles' extromission theory). The origins of modern Optometry are however usually traced back to the $19^{\text {th }}$ century when technological progresses and increased demand for vision testing led to a distinction being made between dispensing and refracting opticians [1].

Nowadays, according to the college of optometrists (UK), "optometrists are primary health care specialists trained to examine the eyes, to detect defects in vision, signs of 
injury, ocular diseases or abnormality and problems with general health". This means they should develop a broad range of competencies such as the ability to use diagnostic drugs to aid ocular examination, to assess symptoms and signs of neurological significance, to fit contact lenses or to advise on and to dispense the most suitable form of optical correction taking into account durability, comfort cosmetic appearance and lifestyle". To acquire these competencies, optometry students have thus to follow a rich curriculum, covering a wide range of topics including: general medical science, visual ergonomics, optics, bioethics, binocular vision, pharmacology, visual psychophysics, neurophysiology, and legal and professional aspects of Optometry.

In this context, students sometimes fail to see the relevance of their education in Optics and engage reluctantly with this topic. This problem is aggravated by the fact that most students see Optics as a difficult subject. This last outcome is not completely surprising as most students are accepted with $A$ levels in Biology, Chemistry and a $3^{\text {rd }}$ topic, usually Mathematics, but very rarely Physics.

In order to evaluate the importance of optics as part of the optometry curriculum, to improve the satisfaction of our students and to best suit their needs as future Optometrists, we first reviewed the place of optics in the optometry curricula across Europe, then carried out a survey among Manchester Optometry alumni asking them how relevant they consider the classic teaching in optics (geometrical, physical and visual optics) to be to their subsequent career.

\section{Optometric Education in Europe}

Important changes took place in Optometric education in Europe in association with the Bologna declaration and the optometrists profile in several countries (e.g. Spain, Portugal) evolved towards the UK model. The practice of Optometry in Europe is however still surprisingly diversified $[2,3]$. The profession is not always officially recognised (e.g. in France), and even in countries where the practice of Optometry has a legal status, regulations present important variations.

In Germany for instance, the clinical / bio-sanitary components represented traditionally a relatively smaller part of the course than in the UK, letting a more important place to Optics related subjects. The professional profile is thus different, more directed towards the development and fabrication of visual aids or related to the Optics industry. On the opposite side, the UK model emphasizes on the biomedical / healthcare, and UK optometrists can perform some medical acts legally restricted in other countries (e.g. using diagnostics drugs). As a consequence, the part of Optics in the curriculum is reduced to accommodate topics such as ocular pathology and pharmacology.

Institutions and regulating bodies throughout Europe tend to affirm however the importance of Optics, and the European Council of Optometry and Optics (ECOO) has chosen for the European Diploma in Optometry to retain the highest standard, combining the strong physics/optics focus of some German Universities' program with the clinical focus of the UK model.

Optics is thus still seen as core to the formation of Optometrists but, in some countries, it does not represent anymore the backbone of the profession. For this reason, we decided to carry out a survey among Manchester Optometry alumni to know how 
relevant they consider the classic teaching in optics (geometrical, physical and visual optics) to be to their subsequent career.

\section{Survey - The point of view of Optometrists}

The survey was carried out with the software SelectSurey.net among optometrists alumni of the University of Manchester / UMIST who had graduated at least four years ago (oldest respondents had graduated in 74). This duration was chosen so that this survey reflected the point of view of experienced optometrists (at least 3 years).

The content and answer rate of the survey are represented in Table 1 . As stated previously, the purpose of the survey was to help re-assess the importance of the quality and quantity of the teaching in optics. The various aspects of optics are usually divided in three components: geometrical (G.O.), physical (P.O.) and visual optics (V.O.) and it is the division followed at the University of Manchester. For each one, we presented the same set of four statements:

- What I learnt during my studies has been useful for me professionally.

- The education I received was appropriate for my career.

- The current amount of geometrical optics taught $(-24 \mathrm{~h})$ should not be reduced.

- I enjoyed the teaching I received.

Responses were given using a standard five-level Likert item ranging from "strongly agree" to "strongly disagree".

The participation rate was good with 37 respondents (i.e. almost 33\%). The results of the survey were globally very positive. A majority of alumni $(>59 \%)$ gave a positive answer to all these questions with Visual Optics clearly the most appreciated topics: $78-94 \%$ of positive answers (i.e. "strongly agree" and "agree") and the only one with a majority of "strongly agree".

For Physical Optics, the prevailing answer shifted to "agree" but results were still highly positive with $75-91 \%$ of positive answers.

The most negative answers were obtained for Geometrical Optics. Although the rate of positive answers is still high (59-67\%, with a dominance of "agree") the first 2 questions, regarding the usefulness of the course and its relevance to a career in Optometry, attracted 11 negative answers ("disagree" and "strongly disagree") compared to 0 for P.O. and 1 for V.O. There is also a surprising $21.63 \%$ who did not found that what they had learned had been useful and $40.55 \%$ ("neutral" and "disagree") who do not object to a reduction in the teaching to less than 24 hours, compared to $24.32 \%$ for P.O. and $16.21 \%$ for V.O.

V.O. is the unit which is the most clearly related to Optometry and the one which relies the less on mathematics. Its positive appreciation could therefore be expected.

The positive answers for P.O. are a bit more surprising but may reflect the fact that P.O., despite being challenging for students with a very limited background in Physics, is stimulating (new concepts (EM wave, polarisation, etc.) are introduced, explanations of natural phenomena are presented) and correspond well to the optometrists' need in an increasingly technological environment. 
The relatively negative results for geometrical optics are the most surprising. G.O. is often used to introduce numerous fundamental concepts (focal plane, image plane, conjugated points, light rays, etc.) which are necessary to teach P.O. and V.O. It is also a topic that can appear as dry and too abstract when compared to V.O., and without the novelty and challenge of P.O. Its limited appreciation probably reflects the desire to acquire a practical knowledge which relates closely with real life applications.

In addition to the series of questions, respondents had the possibility to provide some comments. These comments confirm the answers given to each questions, and underline the importance of Optics for Optometrists. It was stated that refraction and optics are the core strengths of Optometrists, strengths shared unequally with other eyecare professional and should therefore not be dismissed. A background appreciation of optics is important to better understand the visual difficulties met by the patient and provide the optimum correction. It is also useful to demonstrate their professional knowledge to patients if they ask questions (e.g. anti-reflection coatings), as well as to make sense of claims related to commercial instruments. Respondents however stressed that the teaching in Optics should be updated, made more concise and remain focused. Critics about teaching in subjects such as psychophysics, Fourier analysis were recurrent, as well as the place of mathematical ability in tests.

\section{Conclusion}

Even in the UK where the Optometrist profile is one of the less physics-oriented in Europe, the importance of Optics is still affirmed by regulating bodies and optometrists themselves. The question is then how to best deliver a teaching in Optics so as to provide the students with the skills set by the ECOO.

The scope of the profession tends to expand towards the detection, diagnosis and management of ocular diseases, and it is not possible to stretch further the course without increasing its duration. One solution could be to broaden the professional profile of optometry further than the healthcare sector. In addition to a common formation, students could choose different ECTS credits (optics, marketing, customer service, etc.) depending on their professional project, and each University could modulate their teaching by providing optional courses in agreement with its professional surrounding. Several respondents to the survey actually suggested that education in different topics such as business administration or pathology would be useful. The career prospects may however be low in some cases and this solution would have to comply with decisions associated with the ECOO and Bologna declarations.

The simplest solution is probably to modernise the teaching in Optics to best suit the needs of Optometry students. If Optometry progressively distanced itself from Optics, the teaching in Optics for optometrists may have stayed too traditional as can bee seen from the few books dedicated to the subject. The survey showed that this teaching needs to be relevant to optometrists' daily activities and directed towards real life applications. Fortunately, Optometry offers a wonderful potential to introduce all the main optical phenomena and a number of examples are presented in table 2. A sound background in optics is important for the optometrist to understand many recent technological advances (e.g. aberrometer, multifocal implants) [4, 5] and to advise the patients contemplating refractive surgery. It is up to us to brush up our courses to engage with the students and make sure that optics remains a core strength of Optometrists. 


\section{References}

1. Gregg JR. The Story of Optometry. New York: Ronald Press, 1965.

2. Libro Blanco de la Titulación de Grado en Óptica y Optometría. Agencia nacional de Evaluacion de la Calidad y Acreditacion http://www.aneca.es/media/150364/libroblanco optica def.pdf

3. Shehzad A. Naroo, Feike Grit, Optometry and optics in Europe, Contact Lens and Anterior Eye 2009; 32(3): 101-102.

4. Atchison, David A. Editorial: Who needs optics? Clinical and Experimental Optometry 2003, 86(1):1-2.

5. V. Lakshminarayanan, Teaching optics in a multi-disciplinary setting: experience from optometry programs, in 10th International Topical meeting on Education and Training in Optics and Photonics, Proceedings, ed. M. Nantel, SPIE 2007, pages 280-284. 


\section{Table 1}

1. Regarding Geometrical Optics (i.e. light as rays, Snell's law, construction rays, thin lenses, cardinal planes, etc.):

\begin{tabular}{|c|c|c|c|c|c|c|}
\hline & $\begin{array}{l}\text { Strongly } \\
\text { Agree }\end{array}$ & Agree & Neutral & Disagree & $\begin{array}{l}\text { Strongly } \\
\text { Disagree }\end{array}$ & $\begin{array}{l}\text { Response } \\
\text { Total }\end{array}$ \\
\hline $\begin{array}{l}\text { What I learnt during my studies has } \\
\text { been useful for me professionally. }\end{array}$ & $29.73 \%(11)$ & $32.43 \%(12)$ & $16.22 \%(6)$ & $16.22 \%(6)$ & $5.41 \%(1)$ & 37 \\
\hline $\begin{array}{l}\text { The education I received was } \\
\text { appropriate for my career. }\end{array}$ & $18.92 \%(7)$ & $56.76 \%(21)$ & $16.22 \%(6)$ & $5.41 \%(2)$ & $2.7 \%(1)$ & 37 \\
\hline $\begin{array}{l}\text { The current amount of geometrical } \\
\text { optics taught }(\sim 24 \mathrm{~h}) \text { should not be } \\
\text { reduced. }\end{array}$ & $27.03 \%(10)$ & $32.43 \%(12)$ & $27.03 \%(10)$ & $8.11 \%(3)$ & $5.41 \%(2)$ & 37 \\
\hline \multirow[t]{2}{*}{ I enjoyed the teaching I received. } & $27.03 \%(10)$ & $40.54 \%(15)$ & $24.32 \%(9)$ & $5.41 \%(2)$ & $2.7 \%(1)$ & 37 \\
\hline & & & & \multicolumn{2}{|c|}{ Total Respondents } & 37 \\
\hline
\end{tabular}

2. Regarding Physical Optics (i.e. the wave nature of light, interferences, anti-reflections coatings, diffraction, polarisation, etc.):

What I learnt during my studies has been useful for me professionally.

The education I received was appropriate for my career.

The current amount of physical optics taught $(\sim 24 \mathrm{~h})$ should not be reduced. I enjoyed the teaching I received.

\begin{tabular}{|c|c|c|c|c|c|}
\hline $\begin{array}{l}\text { Strongly } \\
\text { Agree }\end{array}$ & Agree & Neutral & Disagree & $\begin{array}{l}\text { Strongly } \\
\text { Disagree }\end{array}$ & $\begin{array}{c}\text { Response } \\
\text { Total }\end{array}$ \\
\hline $0.54 \%$ (15) & $51.35 \%(19)$ & $8.11 \%(3)$ & $0 \%(0)$ & $0 \%(0)$ & 37 \\
\hline $.73 \%(11)$ & $56.76 \%(21)$ & $13.51 \%(5)$ & $0 \%(0)$ & $0 \%(0)$ & 37 \\
\hline $.43 \%(12)$ & $43.24 \%(16)$ & $18.92 \%(7)$ & $2.7 \%(1)$ & $2.7 \%(1)$ & 37 \\
\hline $73 \%(11)$ & $51.35 \%(19)$ & $10.81 \%(4)$ & $5.41 \%(2)$ & $2.7 \%(1)$ & 37 \\
\hline & & & \multicolumn{2}{|c|}{ Total Respondents } & 37 \\
\hline
\end{tabular}

3. Regarding Visual Optics (i.e. optics of the eye, correction of ametropia, aberrations, optical vs neural constraints on visual acuity, optics of ophthalmic instruments and lenses, etc.):

$\begin{array}{lcccccc} & \begin{array}{c}\text { Strongly } \\ \text { Agree }\end{array} & \text { Agree } & \text { Neutral } & \text { Disagree } & \begin{array}{c}\text { Strongly } \\ \text { Disagree }\end{array} & \begin{array}{c}\text { Response } \\ \text { Total }\end{array} \\ \begin{array}{l}\text { What I learnt during my studies has } \\ \text { been useful for me professionally. }\end{array} & 56.76 \%(21) & 37.84 \%(14) & 5.41 \%(2) & 0 \%(0) & 0 \%(0) & 37 \\ \text { The education I received was } & 56.76 \%(21) & 35.14 \%(13) & 5.41 \%(2) & 0 \%(0) & 2.7 \%(1) & 37\end{array}$


appropriate for my career.

The current amount of visual optics taught $(\sim 24 \mathrm{~h})$ should not be reduced.

$51.35 \%$ (19) $32.43 \%$ (12) $\quad 10.81 \%$ (4) $\quad 2.7 \%$ (1) $2.7 \%(1) \quad 37$

I enjoyed the teaching I received.

$45.95 \%$ (17) $32.43 \%(12) \quad 16.22 \%(6)$

$2.7 \%(1) \quad 2.7 \%(1)$

37

Total Respondents

Table 2

\begin{tabular}{|l|l|}
\hline Topic & Illustration in the context of Optometry \\
\hline Geometrical Optics & $\begin{array}{l}\text { Correction of ametropia, telescopes for low vision } \\
\text { patients }\end{array}$ \\
\hline Interferences & Anti-reflection coatings \\
\hline Michelson interferometer & Time-Domain OCT \\
\hline Young's fringes & $\begin{array}{l}\text { Instruments for assessment of visual acuity pre- } \\
\text { cataract surgery }\end{array}$ \\
\hline Polarisation & Polarising sunglasses, Haidinger brushes \\
\hline Birefringence & $\begin{array}{l}\text { Instruments to assess the integrity of the Retinal Nerve } \\
\text { Fibre Layer }\end{array}$ \\
\hline Waveguide & Photoreceptors \\
\hline Aberrations & $\begin{array}{l}\text { Myopia, wavefront sensor (Hartmann-Schack), } \\
\text { Wavefront Guided Laser surgery, aberrations of } \\
\text { lenses, relation between spherical aberration and } \\
\text { depth of field in the context of intraocular implants and } \\
\text { presbyopia }\end{array}$ \\
\hline Chromatic aberrations & Duochrome test \\
\hline Diffraction & Multifocal lenses, resolution, Rayleigh criterion \\
\hline Photometry & Lighting \\
\hline Optical design & $\begin{array}{l}\text { Example of different optical designs that can be found } \\
\text { among the animal kingdom (pinhole eye, compound } \\
\text { eye, etc.) }\end{array}$ \\
\hline Laser & $\begin{array}{l}\text { Refractive surgery, pancoagulations, Nd:Yag posterior } \\
\text { capsulotomy }\end{array}$ \\
\hline
\end{tabular}

